\title{
La justicia en equidad y las violencias contra las mujeres en Colombia*
}

\author{
Fabio Saúl Castro-Herrera** \\ Jefferson Jaramillo Marin***
}

\begin{abstract}
RESUMEN
La administración de justicia en Colombia no cuenta con las estrategias adecuadas para responder a la violencia contra las mujeres (VCM). Este artículo de reflexión derivado de un intercambio investigativo de los autores analiza este tema en tres dimensiones a partir de una perspectiva sociojurídica. En primer lugar, señala algunas limitaciones y restricciones de la administración de justicia frente a las VCM; en segundo lugar, destaca el potencial de la conciliación en equidad en términos de su carácter transformador y reflexivo de las normas sociales y la comprensión integral del conflicto; en tercer lugar, expone un marco propositivo de actuación desde la Conciliación en Equidad en relación con las VCM en Colombia. El artículo propone que la conciliación en equidad, dadas unas condiciones específicas, deviene como estrategia integral para abordar las condiciones de producción de este tipo de violencias.
\end{abstract}

Justicia en equidad - violencia contra las mujeres - gestión de conflictos

* Artículo de reflexión derivado de: a. los acumulados conceptuales que representó la construcción del Módulo de innovación de la labor del conciliador en equidad frente a la violencia contra la mujer realizado en el marco del Proyecto Acceso a la Justicia financiado por USAID entre el 2013 y 2015 y adelantado por la Escuela de Justicia Comunitaria, adscrita a la Facultad de Derecho, Ciencias Políticas y Sociales de la Universidad Nacional de Colombia; b. el diálogo académico entre los autores, en el marco de dos grupos de investigación Política Social y Desarrollo adscrito a la Pontificia Universidad Javeriana y Escuela de Justicia Comunitaria, adscrito a la Universidad Nacional de Colombia. Este artículo amplía y refina conceptual y metodológicamente varias de las discusiones sugeridas en CASTRO, F. y JARAMILLO, J. La justicia en equidad frente a las violencias contra las mujeres (VCM). En: CASTro, Fabio, Ardila A., Edgar y Jaramillo, Jefferson (eds.), Huellas y Trazos de la justicia comunitaria en Colombia. Una década de aportes y desafíos de la EJCUN. Bogotá, Universidad Nacional de Colombia, 2016, pp. 139-147.

** Abogado de la Universidad Nacional de Colombia y Magíster en Estudios Culturales de la Pontificia Universidad Javeriana. Profesor-Investigador de las Universidades Nacional de Colombia y Antonio Nariño. Correo electrónico: fcastroherrera@gmail.com

*** Sociólogo y Magíster en Filosofía de la Universidad del Valle. Doctor en Investigación en Ciencias Sociales de la Flacso, México. Profesor Asociado y Director del Doctorado en Ciencias Sociales y Humanas, Pontificia Universidad Javeriana. Correo electrónico: jefferson.jaramillo@javeriana.edu.co

Artículo recibido el 27 de mayo de 2016 y aceptado para su publicación en este número el 23 de julio de 2018. 


\title{
Justice in equity and the violences against women in Colombia
}

\begin{abstract}
The administration of justice in Colombia has not had the strategies to respond to violence against women (VAW). This article of reflection result from a mutual construction of the authors, analyze this issue in three dimensions, from a socio legal perspective. First, we note some limitations and restrictions of the administration of justice against the VCM; second, we show the potential of conciliation in equity in terms of its transformative and reflective nature of social norms and comprehensive understanding of the conflict. Thirdly we present a framework for action from the Conciliation Equity in relation to VAW in Colombia. The article proposes that conciliation in equity, it becomes as comprehensive strategy to address condition of production this kind of violence.
\end{abstract}

Justice in equity - violence Against women - conflict management

\section{INTRODUCCIÓN}

$\mathrm{L}$ a administración de justicia en Colombia no ha contado con las estrategias adecuadas y eficientes para responder a una de las formas de violencia más comunes en nuestra sociedad: la violencia contra las mujeres (VCM). El artículo propone que la conciliación en equidad, dadas unas condiciones específicas, deviene como estrategia apropiada para posibilitar el abordaje de las condiciones de producción, las prácticas y discursos violentos contra las mujeres.

El artículo considera que la conciliación en equidad es una de las posibilidades subvertoras dentro del campo jurídico hegemónico para gestionar desde algunas de sus condiciones las VCM, en tanto comprende la naturaleza del conflicto que está a la base de estas violencias: estructuras sociales normativas antidemocráticas. Las VCM son concebidas como aquellas acciones de hecho, pero también omisiones que tienen para ellas como resultado posibles o reales daños físicos, sexuales, psíquicos, económicos, patrimoniales, incluidas las amenazas, la coerción o la privación arbitraria de libertad, ya sea que ocurra en la vida pública o privada ${ }^{1}$. Las VCM cobijan acciones contra las mujeres en razón a su edad, su pertenencia étnica racial, su condición socioeconómica o su condición de desplazamiento, discapacidad visual, auditiva, motriz y cognitiva, su orientación sexual o su identidad genérica ${ }^{2}$.

\footnotetext{
${ }^{1}$ Expósito, F. “Violencia de Género”, en Revista Mente y Cerebro, 2011, 48.

${ }^{2}$ Asamblea General de las Naciones Unidas. Convención sobre la eliminación de todas las formas de discriminación contra la mujer (CEDAW), 1979.
} 
Sin ignorar el acervo conceptual construido en torno a las denominadas también como violencias basadas en el género ${ }^{3}$ consideramos que mencionar el fenómeno explícitamente como violencia contra las mujeres es apropiado en virtud de que es una forma particular de violencia que afecta a las mujeres por su condición de género ${ }^{4}$. Desde esta perspectiva las violencias contra las mujeres no acontecen de forma casual, sino que emanan de la condición de discriminación y subordinación estructurales de la población femenina. En adelante, con esta precaución, seguimos la perspectiva de hablar de violencias contra la mujer (VCM).

Estas violencias permean, a partir de dispositivos de poder ${ }^{5}$, la estructura social y las prácticas comunitarias de grupos humanos o sociedades, sean estas tradicionales o contemporáneas, o aquellas abiertas, cerradas, plurales, herméticas o diversas. Su larga persistencia histórica y los esquemas de tolerancia cultural con ellas sitúan a estas violencias dentro de un imaginario común sostenido en el tejido social como mecanismo de control discriminatorio ${ }^{6}$.

La intencionalidad del artículo es aportar viñetas reflexivas críticas desde Colombia respecto de la insistencia en el uso del derecho penal como principal o única estrategia de lucha y que a todas luces se sigue mostrando insuficiente pero también inconveniente a la hora de intervenir estructuralmente en la producción de estas violencias. Esta clave permite concebir que si bien estas violencias no son jurídicamente conciliables, pueden ser susceptibles de reconocimiento crítico en sus diversas lógicas de funcionamiento dentro del quehacer de los actores de la administración de justicia en equidad.

El artículo se estructura en cinco momentos con una perspectiva de análisis sociojurídico que abreva en literatura reconocida en el campo de los estudios sociales y culturales alrededor del género y los análisis críticos del derecho. El primer momento realiza una aproximación de lo que se comprende por justicia en equidad en Colombia. El segundo describe algunas de las debilidades, limitaciones e imposibilidades de la conciliación en equidad frente a las VCM. El tercero discute algunas de las potencialidades desde la

${ }^{3}$ Lemaitre, J. Más allá de la pulsión de castigo: ¿es útil sancionar a los agresores de la violencia conyugal? Congreso Internacional "Una alternativa de acceso a la justicia para las mujeres”. Género, Política y Derecho. 2011. Meertens, D. Género y violencia: Representaciones y prácticas de investigación. En: Robledo, Ángela y Yolanda PuYAna (comps.). Ética: Masculinidades y Feminidades. Bogotá, Universidad Nacional de Colombia, 2000, pp. 89-96 y SEGATO, R. "Violencia y género en la sociedad patriarcal: Las estructuras elementales de la violencia: ensayos sobre género entre la antropología, el psicoanálisis y los derechos humanos”. Bernal, 2003, Universidad Nacional de Quilmes.

${ }^{4}$ Carcedo, A. Comisión de transición hacia el consejo de las mujeres y la equidad de género. El feminicidio en Ecuador. 2010a.

${ }^{5}$ Arensburg, S. y Lewin, E. Comprensión de los nudos institucionales en el abordaje de la violencia contra las mujeres en la pareja: aportes de una lectura feminista a la experiencia chilena. Universitas Humanística, 78, 2014, pp. 187-210. http://dx.doi.org/10.11144/Javeriana.UH78.cniv y Meertens, D. Género y violencia: Representaciones y prácticas de investigación. En: Robledo, Ángela y Yolanda Puyana (comps.). Ética: Masculinidades y Feminidades. Bogotá, Universidad Nacional de Colombia, 2000, pp. 89-96.

${ }^{6}$ Fondo de las Naciones Unidas y el Gobierno de España para el cumplimiento de los Objetivos de Desarrollo del Milenio (UNIFEM, MDGF). Estudio sobre tolerancia social e institucional a la violencia basada en género en Colombia. Programa Integral contra Violencias de Género/UNIFEM/MDGF. Bogotá, 2010. 
Conciliación en Equidad, para pensar en un anclaje teórico básico o mínimo que permita superar o ser sensibles desde el operador de este tipo de justicia, las debilidades e imposibilidades antes expuestas. El cuarto expone un marco propositivo, desde lo que consideramos puede hacer y ser la Conciliación en Equidad en relación con las VCM en Colombia. Termina el artículo con un epílogo, a manera de exposición de recomendaciones operativas dentro de este marco propositivo.

\section{LA ADMINistración DE JUSTICIA EN EQUidAd EN COLOMBia ${ }^{7}$}

En el marco de las nuevas dinámicas de regulación del derecho a nivel global en las décadas de los años ochenta y noventa, y como respuesta a la crisis de la administración de justicia, tienen lugar en Colombia varias reformas judiciales. Un marco políticojurídico englobante de estas reformas fue la Constitución de 1991, que posibilitó que personas particulares de manera transitoria se encarguen de la gestión y administración de conflictos.

Al respecto, el artículo 116 de la Constitución de 1991 señala que los particulares pueden ser investidos transitoriamente de la función de administrar justicia en la condición de conciliadores o de árbitros habilitados por las partes para proferir fallos en derecho o en equidad, en los términos que determine la ley. Las reformas operadas hasta el momento han tenido como común denominador la desconfianza frente a la justicia formal del Estado, porque no la consideran un instrumento eficaz, transparente y adecuado para zanjar las controversias cotidianas; además, responden a la necesidad de sensibilizarse frente a los usos y costumbres comunitarios y a las necesidades ciudadanas de resolver de manera más rápida y consensual sus conflictos ${ }^{8}$.

Una de las reformas que intentó responder a la crisis judicial manifiesta de manera ostensible en la congestión de despachos judiciales, se materializó en la Ley $\mathrm{N}^{\circ} 23$ de 1991, la que dio origen a la Conciliación en Equidad. Posteriormente, con la expedición de la Ley No 446 de 1998, se afianza en el país la idea de la justicia en equidad como instrumento para garantizar el acceso a la justicia y superar la perspectiva de la descongestión. El funcionamiento básico de la figura desde la normatividad asegura que el modelo de administración de justicia otorgue potestad a un tercero imparcial (Conciliador en equidad) para que intervenga en la solución de un conflicto, contribuyendo a la construcción de un acuerdo entre las partes ${ }^{9}$. Ahora bien, ¿Cómo funciona la conciliación en equidad en el país?

\footnotetext{
${ }^{7}$ Los autores aclaran que no es el objetivo, al menos en este texto y también por restricciones de espacio, ofrecer una perspectiva comparada de este tipo de justicia. Sin embargo, reconocen la necesidad y urgencia de avanzar en ulteriores reflexiones en un tipo de perspectiva como estas.

${ }^{8}$ Uprimny, R. "Legitimidad y conveniencia del control constitucional", en Revista de Derecho Público 12, 2001, Bogotá, p. 302.

${ }^{9}$ Castro-Herrera, F. S. "La justicia comunitaria: un aporte a la construcción de paz en poblaciones en situación de desplazamiento". En: Identidades, enfoque diferencial y construcción de paz. Observatorio de Construcción de Paz, Universidad Jorge Tadeo Lozano. 2012.
} 
La Conciliación en equidad es una modalidad de administración de justicia de entronque mixto en la que coparticipan el Estado desde sus formas jurídicas (debido a que es una figura promovida y regulada por la ley) y la comunidad, condición necesaria para la existencia y legitimidad social de la figura. Esta modalidad de administración de justicia funciona en el país bajo ciertos parámetros compartidos y legitimados, a saber:

a. La no profesionalización. Los conciliadores en equidad son personas postuladas por su comunidad para iniciar un proceso de formación regulado por el Ministerio de Justicia a partir del Manual de Implementación de la Conciliación en Equidad (MICE). El proceso se inicia con la construcción de los perfiles sociológica y antropológicamente pertinentes por las comunidades de referencia. Para la postulación no es un requisito legal la formación jurídica o el conocimiento formal del derecho. Sí ser mayor de edad, saber leer y escribir y ser ciudadano en ejercicio. El espíritu de la ley apela a la necesidad de que el operador tenga el conocimiento de las dinámicas sociales de la comunidad que lo postula y la legitimidad ante ella.

b. Proceso de formalización del conocimiento del operador. Organizaciones sociales o universidades se encargan del proceso formativo de los operadores de acuerdo con las instrucciones del MICE (Marco de Implementación de la Conciliación en Equidad) en un período en el que se acrediten ciento veinte horas teóricas y veinte prácticas. Los candidatos que aprueban la evaluación reciben un aval del Ministerio de Justicia, requisito para que la autoridad judicial de mayor jerarquía del municipio expida una resolución en la que se enlista a los nuevos conciliadores en equidad.

c. El sustento de las decisiones están orientados por los valores y normas sociales. Las determinaciones que los conciliadores toman frente a la solución de los conflictos están orientadas por el justo comunitario, que es el conjunto de valores y normas que construyen un criterio de lo justo en una comunidad o contexto social específico, "se le llama en equidad, por cuanto las decisiones que se toman cuentan de manera predominante con la norma social, pero enmarcada en un estatuto legal que las hace válidas ante el sistema judicial nacional" ${ }^{10}$.

d. La administración de justicia en equidad actúa bajo consenso. Es un tipo de administración de justicia consensuada en la que no se resuelve o se decide unilateralmente por el tercero imparcial, es necesaria la participación de las partes como condición sine qua non para construir un acuerdo. En caso de no lograrlo el conciliador les remite a otra instancia para iniciar el proceso judicial indicado.

e. Gratuidad y celeridad. El artículo 83 de la Ley $\mathrm{N}^{\circ} 23$ de 1991 establece que el procedimiento surtido no tiene ningún costo para las partes. Los procedimientos deben ser comprensibles y rápidos, de manera que efectivamente sea una forma de acercar a la administración de justicia al ciudadano de manera oportuna.

f. Procedimientos y competencia. Los conciliadores en equidad podrán actuar ante la solicitud de una de las partes y podrá solicitar a la otra que comparezca. Los

${ }^{10}$ Ardila, E. "Justicia comunitaria y justicia en equidad. Los conceptos y su sentido en Colombia”. En, Edgar, Ardila et al. ¿A dónde va la Justicia en Equidad en Colombia?, Corporación Región, Medellín, 2006, p. 96. 
conciliadores pueden actuar en todas las materias que sean susceptibles de transacción, desistimiento o conciliación. Los acuerdos se suscriben en un acta de conciliación que tiene plenos efectos jurídicos de tránsito a cosa juzgada y mérito ejecutivo en lo que haya sido objeto de la conciliación ${ }^{11}$.

En síntesis, la conciliación en equidad es posible comprenderla en el gozne entre la normatividad jurídica del Estado "que posibilita su existencia y asigna su regulación" y la normatividad social "que proporciona la lectura de la comunidad, sus conflictos y sus formas para resolverlos" 12 . Es precisamente en el anclaje normativo comunitario donde resulta deseable incidir para transformar los patrones culturales que posibilitan la producción de las VCM. Sin embargo, como se ha indicado recientemente en algunos estudios, también existen experiencias en las que el funcionamiento/operación de la figura asume las mismas limitaciones de la administración de justicia del Estado: se comportan bajo un positivismo normativista o un ejercicio instrumental funcional en el que su preocupación está mediada por la descongestión de despachos judiciales ${ }^{13}$.

\section{La Conciliación en Equidad (CE) ANTE la VCM: Limitaciones, DEBILIDADES E IMPOSIBILIDADES}

Aunque para la administración de la justicia en equidad (AJE) la problemática de las VCM no resulta desconocida en cuanto a que muchos de sus procesos se han orientado a la gestión constructiva y transformadora de todos aquellos conflictos que potencialmente pueden devenir en conflictos agudos de diverso tipo, lo cierto es que las relaciones, articulaciones y sensibilidades establecidas con estas violencias no son del todo claras.

No obstante, si para la AJE el tema de las VCM no ha sido fácil de enfrentar, menos aún para el sistema de justicia ordinario que ha focalizado la penalización del asunto con serias limitaciones. De hecho, son varias las autoras que consideran que el afrontamiento de este tipo de violencias por vía penal conlleva a que la víctima del conflicto sea reducida a un lugar pasivo y marginal en un proceso en el que dejan de ser importantes sus derechos y necesidades en la medida que ya no es ella sino el Estado la parte ofendida ${ }^{14}$. Este diseño promueve una relación en la que el victimario encuentra como mejor estrategia negar lo acontecido, justificar la violencia responsabilizando a la víctima; esta termina silenciada en tanto trata de no profundizar en los acontecimientos, los temores, la culpa, la vergüenza, ya que son sentimientos o emociones que resultan irrelevantes en el proceso penal.

\footnotetext{
${ }^{11}$ Ley No 23 de 1991. Artículo 87. Modificado por la Ley No 446 de 1998, artículo 109.

${ }^{12}$ Castro-Herrera, F. S. "La justicia comunitaria: un aporte a la construcción de paz en poblaciones en situación de desplazamiento”, p. 32.

${ }^{13}$ Castro-Herrera, F. S. Justicia comunitaria en el desplazamiento forzado. Un campo jurídico emergente. Bogotá: Universidad Nacional de Colombia, 2016, pp. 44, 45.

${ }^{14}$ Laurrauri, E. Mujeres y sistema penal: violencia doméstica. Euros Editores, Buenos Aires, 2008.
} 
A lo anterior se añade que la denuncia de la violencia en el ámbito penal no es efectiva, según Pitch ${ }^{15}$, por cuanto: a) la mayoría de procesos por maltrato familiar terminan en absolución o condenas leves; b) mucho después de haber presentado la denuncia, la situación ya se ha modificado; c) el potencial simbólico del derecho penal es ineficaz por la dificultad de reducir la violencia a un acontecimiento puntual con dos protagonistas bien definidos en sus papeles de agresor y víctima; d) no proporciona soluciones de tipo práctico como apoyo económico o psicológico; e) el aumento de las penas no mejora la situación de la víctima ni disminuye la incidencia delictiva. En suma, en el proceso la víctima es revictimizada, en tanto se reproducen estereotipos sexistas, las mujeres se sienten sojuzgadas y despiertan sentimientos de culpa, situación que genera desconfianza en las instituciones y se inhiben las denuncias.

Finalmente, el sistema penal es limitado en su eficacia por la precaria y diferencial presencia del Estado en el territorio. De hecho, el acceso efectivo a la justicia en ciertas zonas es una restricción para que las mujeres vean protegidos sus derechos. Existen contextos regionales en los que no se cuenta con una infraestructura mínima que permita ofrecer una justicia próxima; lo llamativo para ser contemplado en el análisis es que, pese a ello, sí hay conciliadores en equidad en el mismo territorio.

Tras este panorama, mostraremos las debilidades, limitaciones y restricciones de la CE respecto de las VCM. En primer lugar, enunciamos las debilidades en términos de insuficiencia, precariedad o incluso inexistencia de perspectivas o enfoques de género. A renglón seguido, señalamos algunas limitaciones de los marcos de implementación y de los manuales de formación de los conciliadores; finalmente, se esbozan las imposibilidades, planteadas por algunos autores y de la literatura ya clásica frente al tema, en torno a que las VCM sean del conocimiento de mecanismos alternativos de solución de conflictos y en nuestro caso de la administración de justicia en equidad. En este apartado señalaremos algunos comentarios críticos en torno al funcionamiento de la conciliación en equidad frente a algunas de las imposibilidades.

\section{- Acerca de las debilidades}

a. La categoría de género no se ha comprendido como perspectiva o enfoque que permita describir e interpretar los conflictos y actuar frente a sus complejas conexiones con las dinámicas locales de poder, o con ciertas institucionalidades comunitarias que las legitiman, las encubren o incluso pueden ayudar a desactivarlas.

b. El género no se ha asumido de forma radical como una categoría política y jurídica relacional de denuncia ${ }^{16}$. Es decir, no solo como una categoría atributiva de roles, sino como el escenario de discusión política para develar la subordinación estructural de las mujeres en sistemas patriarcales.

${ }^{15}$ Piтch, T, La violencia contra las mujeres y su uso político. En: Anales de la cátedra Francisco Suárez 48, 2014, pp. 19-29.

${ }^{16}$ Paredes, J. Hilando fino desde el feminismo comunitario. El Reboso, México, 2008. 
c. La categoría de género tampoco se ha planteado como "brújula” para la orientación del sistema de administración de justicia en el país. Esto último resulta especialmente sensible y crítico, en cuanto al llamado realizado de forma reiterativa por algunas instituciones y actores sociales, de avanzar en el entendimiento profundo de los impactos y efectos a mediano y largo plazo del mecanismo de la conciliación en los casos de VCM. Más aún, porque la utilización de dicho "mecanismo cuestiona la efectividad de la justicia frente a las mujeres que buscan que las entidades les brinden protección y atención en los casos en los que han sido víctimas de violencias" ${ }^{17}$.

\section{- Acerca de las limitaciones}

a. Un análisis detenido demandan los "materiales oficiales" por medio de los cuales se les ha acercado particularmente a los conciliadores en equidad al tema de las VCM. A propósito, podemos identificar dos textos que son constitutivos del anclaje normativo de la conciliación en equidad en Colombia: el Marco de Implementación de la Conciliación en Equidad ${ }^{18}$ (MICE) y el Manual de formación de conciliadores y conciliadoras en equidad en Colombia ${ }^{19}$. En el caso del primero, aunque aparece como una "ruta" para que la Conciliación en Equidad se consolide como alternativa de solución pacífica de los conflictos cuando se habla de las dinámicas de conflictividad y convivencia presentes en los contextos sociales donde esta es susceptible de actuar, no se mencionan en ningún sentido las dinámicas específicas vinculadas con las VCM.

b. Aunque en el MICE se referencia que "el enfoque de formación para la conciliación en equidad transita por la esfera de lo cotidiano y por la intencionalidad de provocar la autorreflexión de las acciones en relación con el contexto inmediato" ${ }^{20}$ tampoco se hace mención a cómo enfrentar procesos autorreflexivos respecto de estas violencias, cuando sabemos que son más comunes y cotidianas en la esfera de actuación de las comunidades.

c. Al analizar, incluso, el plan de estudios propuesto en este Manual y los ejes temáticos de formación del conciliador, no se plantea una reflexión acerca de las implicaciones del sistema sexo-género en el proceso de entendimiento, comprensión de los conflictos, construcción institucional de la figura y su operación frente a una problemática aguda como lo son las VCM.

d. Se habla de una perspectiva de género inclusiva, al menos en el Manual, pero nada se explica al respecto. Es decir, más allá de hacerse explícito este como "requisito

${ }^{17}$ Fondo de las Naciones Unidas y el Gobierno de España para el cumplimiento de los Objetivos de Desarrollo del Milenio (UNIFEM, MDGF), p. 206.

${ }^{18}$ Ministerio del Interior y de Justicia/Corporación Razón Pública. Marco para la Implementación de la Conciliación en Equidad. Corporación Razón Pública, Bogotá, 2009.

19 Ministerio del Interior y de Justicia/Corporación Razón Pública, Manual para la formación de conciliadores y conciliadoras en equidad. Corporación Razón Pública. Bogotá, 2008.

${ }^{20}$ Ministerio del Interior y de Justicia/Corporación Razón Pública. Marco para la Implementación de la Conciliación en Equidad, p. 55. 
artificial", resulta determinante que en un programa de justicia en equidad en Colombia pensemos en lo que implica la inclusión, la transversalidad, la interseccionalidad.

\section{- Acerca de las restricciones}

Un argumento legitimado en el campo jurídico es que la transformación normativa en la última década ha venido asumiendo y deslizándose a nivel global bajo un enfoque criminal. Las legislaciones se han endurecido y el derecho penal se enarbola como el referente llamado a combatir todas las formas de violencias, incluyendo las $\mathrm{VCM}^{21}$. Muestra de lo anterior, en Colombia se promulgó la Ley $\mathrm{N}^{\circ} 1542$ de 2012, según esta, se establece a la violencia intrafamiliar como un delito no conciliable del que la víctima no puede desistir. Este marco permite comprender las razones de quienes argumentan a favor de la improcedencia de la conciliación en casos de $\mathrm{VCM}^{22}$; y las que encuentran un común denominador en los siguientes elementos:

a. Asimetría de poder. La mujer víctima de la violencia está involucrada en una relación de poder asimétrica en la que cualquier tipo de negociación resultaría desigual. Se sostiene que, como parte de la lógica de la intimidación, resultaría inconveniente o incluso peligroso discrepar con el victimario. Se considera que una asimetría anterior y de carácter estructural es la desigualdad de género. La conciliación en equidad aboga por el empoderamiento de las partes, es decir, que las personas que van a concertar los acuerdos tengan la misma o similar posición de poder en la negociación. De no conseguirlo la negociación resulta impracticable no solo para el caso de la VCM sino en otros casos en los que la subordinación sea manifiesta. Por otra parte, la flexibilidad de la figura permite que se inicien procesos de negociación sin la obligatoriedad de que las personas en conflicto tengan encuentros directos o cara a cara. Otras figuras de la justicia comunitaria como los palabreros de los pueblos Wayuu lo hacen en casos de violencia letal en la que el encuentro conciliatorio es inapropiado. En estos casos la legitimidad del operador y la posición de la comunidad como garante es fundamental. Como remarcaremos a lo largo del artículo, la intervención no trata de atenuar, negar o invisibilizar la violencia manifiesta, mucho menos en llegar a acuerdos acerca de la violencia. Lo que hemos dicho es que, por ejemplo, la violencia física es apenas una pieza del ajedrez.

b. Inadecuada capacitación de los C.E. En términos generales, los actores de la conciliación no cuentan con información suficiente y profunda frente a las problemáticas del género y la relación con las VCM. En consecuencia, se encargarán de reproducir

${ }^{21}$ Pitch, T., "La violencia contra las mujeres y su uso político". En: Anales de la cátedra Francisco Suárez y Echeverry, Y.; Jaramillo, J. "Derecho penal de enemistad. Aproximaciones críticas al debate". En Revista Científica Guillermo de Ockham, 9 (1), 2011, pp. 55-79.

22 Casas, Lidia, Riveros, Francesca y Vargas, Macarena. Violencia de género y la Administración de Justicia. Universidad Diego Portales/Servicio Nacional de la Mujer, Santiago de Chile, s.f. Lemaitre, J. Más allá de la pulsión de castigo: ¿es útil sancionar a los agresores de la violencia conyugal? Congreso Internacional "Una alternativa de acceso a la justicia para las mujeres" y OrmaCHEA, I. "Violencia Familiar y Conciliación”, en Derecho (52), 1999, pp. 75-106. 
estereotipos y creencias respecto de valores conservadores que actúan en contra de la mujer vulnerada. En efecto, este es uno de los riesgos de la conciliación en equidad desde la perspectiva de las estructuras normativas. Por esta razón, es necesario ajustar los procesos formativos en los que se le dé la centralidad a las problemáticas del género en la administración de justicia.

c. Si la VCM se intenta conjurar por vía de la conciliación, se banaliza el acto. Es decir, se considera que la conciliación transmite socialmente la idea perversa de que no representa un comportamiento grave para la sociedad. Sustituir el derecho penal por la conciliación es asumir que existe un comportamiento delictivo que no merece sanción penal. Sin embargo, es necesario matizar en que no se trata de conciliar la violencia, sino de entender que uno de los problemas es el de la simplificación de la misma, es decir, que la intervención de la administración de justicia se realiza sobre hechos puntuales y no sobre las diferentes condiciones de producción que la permiten y la legitiman socialmente. El mensaje de la justicia en equidad debe ser la atención frente a un hecho grave que demanda de una intervención interinstitucional, multiactorial y multiproceso en el que la figura de la conciliación tiene una participación más amplia y profunda.

d. La conciliación no puede brindar garantías efectivas y sostenidas para que se suspenda la violencia o se profundicen las medidas de protección. La conciliación debe facilitar decisiones como el abandono del hogar del perpetrador, la separación inmediata del mismo. El operador al estimular que se hable de la violencia que habitualmente no se hace por vergüenza o temor, promueve una acción pedagógica en el que se entiende que se está ante un hecho grave, que puede terminar en un asesinato.

e. En un proceso de conciliación se corre el riesgo que el conciliador en su afán de construir un acuerdo ponga en la misma condición a la víctima y el victimario, es decir, que la víctima termina asumiendo responsabilidades y culpas que no le corresponden.

\section{Los potenciales de la Conciliación EN EQuidad (CE) ANTE LA VCM}

Desde la CE es clave pensar en un anclaje teórico básico o mínimo que permita superar, o al menos abrir la arena de reflexión en el quehacer de los conciliadores acerca de la importancia de reconocer de forma profunda las debilidades e improcedencias antes expuestas. Específicamente, interesa exponer en esta parte del texto en qué medida la justicia en equidad puede asumir y posicionarse frente a las VCM, por vía de la comprensión del papel de las normas sociales, el rol del conflicto y la dimensión procesual de las violencias directas, estructurales y culturales. En cada uno de estos aspectos señalamos el papel del conciliador ${ }^{23}$ y el proceso formativo del mismo.

${ }^{23}$ Utilizamos un lenguaje neutro solo para no atiborrar el texto y no con el ánimo de perpetuar una narrativa sexista. 


\section{- Las normas sociales en las estructuras violentas y el papel de ellas en la CE}

La relación entre comunidad y normas sociales es central cuando se trata de abordar la justicia en equidad. Y lo es, porque la justicia en equidad se sostiene sobre la base de un conjunto de comportamientos que son acordados y sedimentados colectivamente ${ }^{24}$. Uno de los retos que tienen los operadores de justicia en equidad en los territorios es la identificación de aquellas normas que orientan los devenires cotidianos de las personas pertenecientes a una comunidad y desde allí provocar la lectura y mapeo de los diferentes tipos de conflictividad que hacen presencia en los diferentes niveles de interacción de la vida social. La norma social, por tanto, es el fundamento de las interacciones sociales y estas son las que determinan cómo debemos actuar o qué debemos hacer en determinados contextos. Estas son el adherente o el "teflón” social que genera la producción y reproducción de los valores.

La existencia de normas sociales que instituyen prácticas violentas en detrimento de un sector poblacional con diferencias de género es un factor determinante para comprender el "común denominador" que soporta las VCM. Además, cuando actitudes violentas se normalizan en la cotidianidad de las prácticas, la cultura resulta siendo un "paraguas de exclusión" donde escampa como "natural" el que algunos estén excluidos, estigmatizados, violentados o etiquetados como ciudadanos de segunda o tercera categoría. Si una cultura tiene contenido patriarcal, la estructura social con sus instituciones y su diversidad de expresiones territoriales adquiere un tinte opresor. En esa medida, la base de la inequidad estructural se encuentra en las relaciones opresivas del día a día que habría que contribuir a superar y desmontar.

Una idea central que reconocemos en este artículo y esbozada también por los feminismos críticos, es la de que la masculinidad o el mandato de masculinidad es una construcción sociocultural fundamentada en normas proclives a las violencias ${ }^{25}$. En esa medida, consideramos que buena parte de las VCM tienen como referencia un arquetipo viril, y el funcionamiento de la sociedad bajo las normas del patriarcado. Arquetipo que es necesario subvertir en el orden de lo simbólico para poder tener efecto también en el terreno de lo material, y viceversa ${ }^{26}$.

Para desmontar estos esquemas de percepción y acción, la intervención desde la norma jurídica resulta limitada e insuficiente, en virtud de la imposibilidad de interacción con las realidades concretas de un fenómeno tan complejo y multidimensional como el de las violencias. El ejemplo es sencillo, la norma jurídica protege a la mujer y

${ }^{24}$ Ardila, E. "Justicia comunitaria y justicia en equidad. Los conceptos y su sentido en Colombia"; y Ardila, E., Gamba, R. y Ramírez, L. "La justicia en equidad como proceso social”. En, Edgar Ardila et al. ¿A dónde va la Justicia en Equidad en Colombia? Corporación Región, Medellín, 2006, pp. 133-147.

${ }^{25}$ Segato, R. "Violencia y género en la sociedad patriarcal: Las estructuras elementales de la violencia: ensayos sobre género entre la antropología, el psicoanálisis y los derechos humanos”, 2010, p. 17.

26 Fisas, V., Cultura de Paz y Gestión de Conflictos. UNESCO/Icaria. Barcelona, 1998; JimÉnez, P. "Experiencias de justicia comunitaria desde una perspectiva de género: Realidades y potencialidades"; Fernández, A. La mujer de la Ilusión. Paidós. Argentina, 2010. 
sanciona las violencias que suceden en su persona por su condición; sin embargo, pese a que la normativa jurídica considera esto de obligatorio cumplimiento, el comportamiento antijurídico es el de mayor presencia en buena parte de las sociedades, situación de la que podríamos concluir que la introducción de tipos penales no garantiza su aplicación ${ }^{27}$.

Con lo anterior, queremos señalar que si bien resulta relevante para las agendas feministas y organizaciones sociales que jurídicamente se cuente con protección y sanción directa y efectiva para este tipo de comportamientos, la medida puede resultar necesaria pero insuficiente si tomamos en cuenta que no interviene sobre las estructuras sociales que la hacen posible y que la víctima tampoco encuentra soluciones garantistas en el proceso penal. En este escenario consideramos que la CE tiene un marco de acción integrado y amplio en tanto las condiciones a trasformar están sustentadas en la bisagra entre las normas sociales y las normas jurídicas.

\section{- El rol del conflicto y el lente de las VCM}

A través del lente de las VCM podemos leer las desigualdades históricas y la subordinación de las mujeres en tanto lo masculino se convirtió en el referente bajo el que se organiza el mundo, las instituciones, la democracia y, por supuesto, la justicia ${ }^{28}$. En tal dirección, percibimos que estas situaciones nos sitúan frente a unas contradicciones profundas que son expresión de conflictos estructurales.

De acuerdo con lo anterior sostenemos que la noción de conflictos estructurales permite conectar las VCM con todas aquellas disputas desiguales por el acceso a recursos sociales, económicos, culturales y simbólicos en los que es evidente la dominación masculina ${ }^{29}$.

En esta dirección, vamos a apoyarnos en uno de los aportes centrales del feminismo ${ }^{30}$, el que nos sitúa en la óptica de vincular la relación conflictual de las categorías que constituyen el género, a otras categorías que se imbrican de forma interseccional con diferencias estructurales articuladas a relaciones de clase, de identidad étnica, de orientación sexual y de procedencia. En suma, es crucial abordar con el conciliador en equidad el reconocimiento del desequilibrio social estructural, donde la lectura respecto de la desigualdad en las comunidades no resulta suficiente desde la categoría del "ser mujer”, sino que demanda aproximaciones y observaciones más complejas del campo

${ }^{27}$ Laurrauri, E. Mujeres y sistema penal: violencia doméstica.

${ }^{28}$ Facio, A. y Fries, L. (eds.). “Feminismo, género y patriarcado”. En: Género y Derecho. Colección Contraseña. 1999 y Rubin, G. "El tráfico de mujeres. Notas sobre la 'economía política del sexo”. Nueva Antropología. VIII, 30, 1975, pp. 95-145.

${ }^{29}$ Bourdieu, P. La dominación masculina. Anagrama. Barcelona, 2010.

${ }^{30}$ Segato, R. "Violencia y género en la sociedad patriarcal: Las estructuras elementales de la violencia: ensayos sobre género entre la antropología, el psicoanálisis y los derechos humanos"; Lugones, M. "Colonialidad y género", en Revista Tabula Rasa. 9, 2007, pp. 73-101 y Gargallo, F. "Feminismo latinoamericano", en Revista venezolana de estudios de la mujer, 12 (28), 2007. 
social que relacione e integre en el debate todas estas categorías sociales desde las cuales también se segrega ${ }^{31}$.

\section{- El marco de las violencias directas, estructurales y culturales para comprender las VCM}

Pese a que hoy contamos con diversas hitos y normatividades que prohíben y sancionan la violencia contra las mujeres, los índices de agresión no cesan ${ }^{32}$. En ese sentido, un acercamiento al tema de las VCM y de género debe hacerse partiendo de la lectura comprehensiva e integral del concepto de violencia. Para explicar el fenómeno de la violencia consideramos una perspectiva ya clásica, la de Johann Galtung ${ }^{33}$, la que aborda de forma integral tres tipos de violencia comunes en las esferas de la sociedad ${ }^{34}$. La primera de ellas es la violencia directa, que es la acción más visible y material de violencia en términos físicos, psicológicos y simbólicos. La segunda es la cultural, que está más profundamente enraizada en los valores tradicionales de una sociedad y en la estructura normativa de un tejido social. La tercera es la estructural, intrínseca a los fundamentos del sistema de equidad y solidaridad en una sociedad en un momento histórico dado.

En el primer caso, es importante abordar con los conciliadores en equidad la visibilización de acciones asociadas con el maltrato físico y psicológico. En el segundo caso, reconocemos que el trabajo con los conciliadores en equidad debe estar orientado a producir debates situados desde los territorios, comunidades e institucionalidades, que avancen en un sentido de descolonización de saberes y prácticas ${ }^{35}$ alrededor de los discutibles valores de la caballerosidad, de la cultura de la superioridad masculina, de los comportamientos que sitúan en estado de indefensión a la mujer frente al hombre.

En el tercer caso, el trabajo con los conciliadores debe estar orientado a hacer operativa la categoría de género como una categoría política y jurídica relacional de denuncia en el quehacer de la conciliación en equidad. Es decir, formarlo para mapear en un trabajo

${ }^{31}$ Viveros, M. y Gregorio, C. "Presentación Dossier Sexualidades e interseccionalidad en América Latina, el Caribe y su diáspora”, en Revista Estudios Sociales, 49, 2014, pp. 9-16.

32 Según la Encuesta Nacional de Demografía y Salud en Colombia realizada el 2010, el 37\% de las mujeres aseveran haber sido maltratadas físicamente por su pareja. El $65 \%$ de mujeres afirman que sus compañeros sentimentales han ejercido control sobre ellas de diversas formas. Según el Instituto Nacional de Medicina Legal y Ciencias Forenses, en el 2012, 47.620 mujeres fueron agredidas por su pareja o expareja en Encuesta Nacional de Demografía y Salud (ENDS). Capítulo XII: Violencia contra las mujeres y los niños, 2010. "Aproximadamente, por cada nueve mujeres que reportan ser víctimas de violencia por parte de su pareja o expareja, solo un hombre reporta lo mismo".

33 Galtung, J. "Violence, Peace and Peace Research”, en Journal of Peace Research, 6 (3), 1969, pp. 167191 y Galtung, J., Violencia Cultural. Centro de Investigación por la Paz. Gernika Gorgoratuz, España, 2003.

${ }^{34}$ El sistema Sofía identifica 13 formas de violencias complejas que afectan directamente a las mujeres: violencia física, sexual, económica, patrimonial, emocional, verbal, simbólica, por prejuicio, privada, pública, política, sociocultural, asociada con el conflicto armado (Corporación Humanizar, 2010). Consideramos que todas estas formas pueden estar agrupadas bajo las tres grandes categorías que desarrolla en GALTUNG, J. "Violence, Peace and Peace Research" y Galtung, J. Violencia Cultural.

35 Gargallo, F. "Feminismo latinoamericano", en Revista venezolana de estudios de la mujer. 
colaborativo con la comunidad, la explotación, el patriarcado y la exclusión o en sus múltiples manifestaciones y sobre todo a ser conscientes que estos no son ejecutados específicamente por individuos, sino que son parte de una estructura y están, la mayoría de las veces, fundamentados y sedimentados en instituciones "legítimas".

\section{UN MARCO PROPOSITIVO EN CONSTRUCCIÓN PARA LA INTERVENCIÓN DEL CONCILIADOR Y CONCILIADORA DE CARA A LAS VCM}

En este apartado brevemente mostramos una propuesta desde lo que consideramos puede hacer la justicia en equidad frente a las VCM. En esa dirección, sostenemos como urgente preparar a los conciliadores para desplegar intervenciones orientadas a contrarrestar los impactos y la reproducción cultural del comportamiento, mediante actuaciones que promuevan las garantías y el acceso a la justicia de las personas en conflicto. Desde nuestra óptica existen tres ventajas directas e integrales de la CE.

La primera es su capacidad de acompañamiento situado en cualquier momento del conflicto. El conciliador, por solicitud de una de las partes, puede construir escenarios de negociación antes de que se presente el conflicto destructivo o las dinámicas de escalada (prevenir); puede intervenir en el conflicto propiamente dicho mediante la construcción de acuerdos o toma de decisiones que apunten a solucionar de manera justa la situación (resolver); incluso si no se logra la gestión del conflicto, acompaña para que no trascienda la violencia (contener), es decir, el conflicto sigue presente bajo unas condiciones de no agresión.

La segunda es la capacidad para abordar íntegramente el conflicto. El funcionamiento de este tipo de administración de justicia está orientado a comprender que la violencia no es exclusivamente el acto que materializa el daño, sino un proceso que acumula diversas manifestaciones, muchas de ellas imperceptibles para la víctima y que habitualmente devienen en dinámicas de escalada. Una valoración de este modo nos permite identificar violencias que no son reconocidas como tales por las partes confrontadas, pero que de forma ostensible son parte de un circuito de vejámenes que van a empezar a empeorar.

La tercera es el potencial restaurativo de la conciliación. Gestionar integral y transformadoramente el conflicto, también pasa por preocuparse fundamentalmente de la relación y del daño causado. Mientras que en un procedimiento retributivo los esfuerzos están destinados a probar delitos, establecer culpas y castigos; a contrapelo, la conciliación se ocupa de la transformación del conflicto, de asumir responsabilidades y de responder por el daño causado. Si bien no se trata de desconocer el pasado y la vulneración de la víctima, aquí lo fundamental es situarnos en una perspectiva de futuro de la relación ${ }^{36}$, que no necesariamente es la reconciliación. El reconocimiento de estas tres ventajas se realiza en tres niveles: a. comprensión-detección y visibilización de las conflictividades;

36 GonZÁles, I. "Justicia restaurativa en violencia intrafamiliar y de género". En Revista de Derecho Vol. XXVI, 2013, p. 225. 
b. sensibilización-acompañamiento en los contextos de producción y con los sujetos y comunidades legitimadoras de las VCM; c. articulación con el sistema local de justicia, específicamente con las instancias judiciales que pueden actuar directamente frente a estas formas de violencia por competencia directa.

El nivel de la comprensión -detección y visibilización, debe entenderse en dos registros: a. como escenario conceptual del proceso de formación y de lectura de su contexto más cercano; b. como momento estratégico de la gestión del conflicto en la que el conciliador valora y comprende la multiplicidad de aristas del conflicto. En este nivel, el conciliador reconoce que los conflictos cumplen con determinadas funciones en la sociedad. Es decir, que buena parte de ellos pueden resultar constructivos de acuerdo con el comportamiento de las partes implicadas y al uso de las estrategias en su dinámica; sin embargo, es necesario que detecte cuándo existen condiciones en que las consecuencias de los conflictos son claramente destructivas. Un ejemplo de ello lo encontramos cuando profundizamos en el análisis de conflictos que están vinculados a las VCM, que en sus dinámicas de escalada pueden generar consecuencias catastróficas.

En este primer nivel de acción, la visibilización adquiere un valor como acción de cambio. Es decir, nombrar es empezar a cambiar. De hecho, "al nombrar el problema de la violencia, sacándolo del ámbito privado y moral para centrarlo en el terreno público, ético y político, [se está obligando] a las sociedades a reconocerlo y a posicionarse al respecto. De esta postura, se derivarán también las acciones que emprenda el Estado" 37 .

El nivel de sensibilización-acompañamiento en los contextos de producción y con los sujetos y comunidades legitimadoras de las VCM permite realizar un proceso de formación en dimensiones más específicas luego del mapeo contextual acerca de estructuras y dinámicas de estas conflictividades y una intervención más precisa e informada en la gestión del conflicto. Entendemos los contextos de producción como aquellos espacios donde potencialmente la diferencia de poder es ostensible o manifiesta en términos de la subordinación de la mujer o el privilegio de lo masculino. En esta dirección retomamos lo planteado por Carcedo, quien define los escenarios de feminicidio como "los contextos socioeconómicos, políticos y culturales en los que se producen o se propician relaciones de poder entre hombres y mujeres, particularmente desiguales, y que generan dinámicas de control, violencia contra las mujeres, y feminicidio que adoptan o incluyen características propias”. (2010b, p. 15). Es evidente que la VCM se puede presentar en cualquier contexto y la acción y comprensión se debe generar, en una primera instancia, en el sistema de creencias y en la pérdida de legitimidad de la violencia, como mecanismo de desactivación de violencias culturales ${ }^{38}$.

Finalmente, el tercer nivel es el de la articulación de las acciones del operador de justicia en equidad con el sistema local de justicia, entendido este como "las dinámicas de interacción entre operadores de justicia, otras entidades del Estado y la dirigencia social local con

${ }^{37}$ Carcedo, A. Comisión de transición hacia el consejo de las mujeres y la equidad de género, p. 19.

38 Castro-Herrera, F. S., "La justicia comunitaria: un aporte a la construcción de paz en poblaciones en situación de desplazamiento”, p. 268. 
el propósito de responder a las necesidades de gestión de conflictos en la comunidad y la garantía de derechos. En el nivel local, se define y se construye como un conjunto de políticas públicas y acciones orientadas a garantizar los derechos y tramitar las controversias" 39 . Estas interacciones se logran a partir de planes de trabajo que permitan concertar acciones conjuntas entre los operadores y otras instancias judiciales, de esa manera podemos garantizar que se intervengan las violencias de manera oportuna, eficaz e integralmente.

\section{Epílogo: ReCOMENDACIONES Operativas}

En relación con estos tres niveles, la pregunta es ¿cómo hacer operativo este marco propositivo en los procesos de la administración de justicia en equidad del país? En esa dirección, proponemos las siguientes claves operativas:

a. Diseñar una estrategia institucional de enfoque de género y justicia en equidad, que involucre actores de cada uno de los niveles que conforman el campo de la administración de justicia. Es necesario que los funcionarios y las entidades que se encargan del proceso de implementación, los operadores propiamente dichos y los gobiernos locales integren una mirada en torno al género y entiendan las repercusiones que tiene dicha perspectiva.

b. Incidir en el dispositivo pedagógico en donde se implementa la conciliación en equidad. Lo podemos enunciar en términos de lo temático, es decir, qué se debe instalar en los contenidos y en el proceso formativo en general. Insertar la categoría de género y su perspectiva ético-política. Las primeras personas que deben estar enteradas y formadas en torno al funcionamiento de los dispositivos culturales que alimentan los imaginarios colectivos frente a la permisividad de un fenómeno de violencia, deben ser los conciliadores en equidad y los funcionarios que hacen parte de la estructura institucional de la justicia en equidad.

c. Los conciliadores deben entender la complejidad de las VCM para que logren transmitir claramente a las partes que toda forma de violencia es un asunto grave que demanda ser tratado de manera integral. Trabajar con las personas involucradas en el conflicto es central, informándoles que no están frente a una situación convencional que se resuelve exclusivamente con el arrepentimiento o con la sanción judicial. En particular con las VCM, debemos pensar en que el conciliador debe conocer que estas medidas integrales pueden ser de apoyo psicológico, y seguimiento constante por parte de la institucionalidad estatal y comunitaria. Además, exige la construcción de acuerdos de medidas que garanticen siempre los derechos de la víctima. La conciliación en equidad debe ser parte del conjunto de medidas que se recomienda emplear para el tratamiento integral de la situación.

${ }^{39}$ ARDILA, Edgar. ¿Qué es y para qué sirve un Sistema Local de Justicia? Volumen 1. PNUD. Bogotá, 2015. 
d. Construir una analítica compleja de la violencia que funcione como guía para los conciliadores, de tal manera que entiendan y asuman que la acción violenta no se puede tratar como un acontecimiento aislado o suelto. No es una pieza de ajedrez solitaria en un tablero. Es decir, no podemos reducir la violencia a un hecho o a un solo impacto. Tampoco podemos reducirla a una taxonomía de daños. La labor de los conciliadores es ser sensibles a cada uno de estos casos, y en particular cuando las VCM han sido antecedidas por otros acontecimientos que eran indicativos que el conflicto venía en escalada, o que hacían parte de un continuum de violencias de las que solo se hicieron tangibles las de orden físico.

e. La conciliación en equidad es un mecanismo de intervención situado y sensible a las partes en conflicto, donde ellos deciden voluntariamente si lo toman o no para gestionar un conflicto. Esta intervención exige tener en cuenta siempre no provocar más daño y, por tanto: a. escuchar a las partes por separado; b. establecer el nivel de intimidación de la víctima; c. establecer la gravedad o temperatura de la violencia; establecer la frecuencia del comportamiento violento; d. recordar que estamos en una situación desigual de poder frente a lo que debemos asumir el rol de equilibradores; e. Identificar el deseo de la víctima en la situación; f. establecer el impacto en las redes: terceros afectados; g. establecer si la conciliación es el medio idóneo.

\section{BIBLIOGRAFÍA}

Agatón Santander, Isabel. Justicia de género: un asunto necesario. Bogotá: Editorial Temis, 2013.

Asamblea General de las Naciones Unidas. Convención sobre la eliminación de todas las formas de discriminación contra la mujer (CEDAW), 1979.

Ardila, Edgar. ¿Qué es y para qué sirve un Sistema Local de Justicia? Volumen 1. Bogotá: PNUD, 2015.

Ardila, Edgar. "Justicia comunitaria y justicia en equidad. Los conceptos y su sentido en Colombia”. En, Edgar Ardila et al. ¿A dónde va la Justicia en Equidad en Colombia? Medellín: Corporación Región, 2006, pp. 75-100.

Arensburg, S. y Lewin, E. "Comprensión de los nudos institucionales en el abordaje de la violencia contra las mujeres en la pareja: aportes de una lectura feminista a la experiencia chilena", en Universitas Humanística, 78, 2014, pp. 187-210. http://dx.doi.org/10.11144/ Javeriana.UH78.cniv

Bedoya, Juliana. "En Colombia cada año 35.000 mujeres son maltratadas por sus parejas". Revista Semana (en línea), 22 de noviembre de 2006 (fecha de consulta 23 de septiembre de 2011). Disponible en http://www.semana.com/on-line/colombia-cada-ano-35000-mujeresmaltratadas-parejas/98417-3.aspx. 23/09/11.

Bourdieu, Pierre. La dominación masculina. Barcelona: Anagrama, 2010.

Carcedo, Ana. Comisión de transición hacia el consejo de las mujeres y la equidad de género. El feminicidio en Ecuador, 2010 a.

Carcedo, Ana (Coordinadora). Ni aceptamos ni olvidamos: el feminicidio de Centroamérica 2000-2006., San José C.R: CEFEMINA, 2010b.

Casas, Lidia, Riveros, Francesca y VArgas, Macarena. Violencia de género y la Administración de Justicia. Santiago de Chile: Universidad Diego Portales/ Servicio Nacional de la Mujer, s.f. 
Castro-Herrera, Fabio Saúl. "La justicia comunitaria: un aporte a la construcción de paz en poblaciones en situación de desplazamiento". En: Identidades, enfoque diferencial y construcción de paz. Observatorio de Construcción de Paz, Bogotá: Universidad Jorge Tadeo Lozano, 2012.

Castro-Herrera, Fabio Saúl. Justicia comunitaria en el desplazamiento forzado. Un campo jurídico emergente. Bogotá, Colombia: Universidad Nacional de Colombia, 2016.

Castro, Fabio y Jaramillo, Jefferson. "La justicia en equidad frente a las violencias contra las mujeres (VCM)”. En: Fabio Castro, Edgar Ardila A y Jefferson Jaramillo (eds.), Huellas y Trazos de la justicia comunitaria en Colombia. Una década de aportes y desafíos de la EJCUN. Bogotá, Universidad Nacional de Colombia, 2016, pp. 139-147.

CorPoración para el Desarrollo Humanizar, Sistema SOFIA (Sistema Orgánico, Funcional, Integral y Articulador para la protección a las Mujeres Victimas de Violencias. Sabiduría al servicio de la vida y la dignidad de las mujeres. Bogotá: Corporación para el desarrollo Humanizar, 2010.

Echeverry Enciso, Yesid; Jaramillo Marín, Jefferson. "Derecho penal de enemistad. Aproximaciones críticas al debate", en Revista Científica Guillermo de Ockham, 9 (1), 2011, pp. 55-79.

EnCUeSta Nacional de Demografía y Salud (ENDS 2010). Capítulo XII Violencia contra las mujeres y los niños, p.http://www.profamilia.org.co/encuestas/Profamilia/Profamilia/images/ stories/PDF-capitulos/Capitulo-13.pdf

Expósıto, Francisca. "Violencia de Género". Revista Mente y Cerebro, 48, 2011.

FACIO, Alda y Fries, Lorena (Eds). "Feminismo, género y patriarcado", en Género y Derecho. Colección Contraseña. 1999.

Fernández, A. La mujer de la Ilusión. Argentina: Paidós, 2010. Fondo de las Naciones Unidas y el Gobierno de España para el cumplimiento de los Objetivos de Desarrollo del Milenio (UNIFEM, MDGF). 2010.

Estudio sobre tolerancia social e institucional a la violencia basada en género en Colombia. Bogotá: Programa Integral contra Violencias de Género/UNIFEM/MDGF.-Fisas, Vicent. Cultura de Paz y Gestión de Conflictos. Barcelona: UNESCO/Icaria, 1998.

Galtung, Johan. "Violence, Peace and Peace Research". Journal of Peace Research, 6 (3), 1969, pp. 167-191.

Galtung, Johan. Violencia Cultural. Centro de Investigación por la Paz. España: Gernika Gorgoratuz, 2003.

Gargallo, Francesca. Feminismos desde Abda Ayala. Ideas y proposiciones de las mujeres en 607 pueblos en Nuestra América. México: Corte y confección, 2014.

Gargallo, Francesca. Feminismo Latinoamericano. Revista venezolana de estudios de la mujer, 12 (28), 2007.

GonZÁles RAMíREZ, Isabel Ximena. Justicia restaurativa en violencia intrafamiliar y de género. En: Revista de Derecho Vol. XXVI, 2013.

JiméneZ, Paola. "Experiencias de justicia comunitaria desde una perspectiva de género: Realidades y potencialidades". En, Edgar Ardila et al. ¿A dónde va la Justicia en Equidad en Colombia? Medellín: Corporación Región, 2006, pp. 293-306.

Laurrauri, Elena. Mujeres y sistema penal violencia doméstica. Buenos Aires: Euros Editores, 2008.

Lemaitre, Julieta. Más allá de la pulsión de castigo: ¿es útil sancionar a los agresores de la violencia conyugal? Congreso Internacional "Una alternativa de acceso a la justicia para las mujeres”. Género, Política y Derecho, 2011.

Lugones, María. "Colonialidad y género", en Revista Tabula Rasa. 9, 2007, pp. 73-101.

Lugones, María. Hacia un feminismo descolonial. La manzana de la discordia. 6 (2), 2011, pp. 105-119. 
Meertens, Donny. "Género y violencia: Representaciones y prácticas de investigación”. En: Robledo, Ángela y Yolanda Puyana (comps.). Ética: Masculinidades y Feminidades. Bogotá: Universidad Nacional de Colombia, 2000, pp. 89-96.

Ministerio del Interior y de Justicia/Corporación Razón Pública. Marco para la Implementación de la Conciliación en Equidad. Bogotá: Corporación Razón Pública, 2009.

Ministerio del Interior y de Justicia/Corporación Razón Pública, Manual para la formación de conciliadores y conciliadoras en equidad. Bogotá: Corporación Razón Pública, 2008.

Ormachea C., Iván. Violencia Familiar y Conciliación. Derecho (52), 1999, pp. 75-106.

Paredes, Julieta. Hilando fino desde el feminismo comunitario. México: El Reboso, 2008.

Piтch, Tamar. "La violencia contra las mujeres y su uso político". En: Anales de la cátedra Francisco Suárez 48, 2014, pp. 19-29.

Rubin, G. El tráfico de mujeres. Notas sobre la "economía política del sexo. Nueva Antropología. VIII, 30, 1975, pp. 95-145.

SEgATO, Rita Laura. Las estructuras elementales de la violencia: ensayos sobre género entre la antropología, el psicoanálisis y y los derechos bumanos. Prometeo: Buenos Aires, 2010.

UPRIMnY, Rodrigo. "Legitimidad y conveniencia del control constitucional”, en Revista de Derecho Público 12, 2001.

Viveros V., Mara y Gregorio G., Carmen. "Presentación Dossier Sexualidades e interseccionalidad en América Latina, el Caribe y su diáspora”. Revista Estudios Sociales, 49, 2014, pp. 9-16. 
